2020-01-01

\title{
Ikonos satellite imagery for ndvi related assessment applied to land clearance studies
}

\section{Lavers, CR}

http://hdl.handle.net/10026.1/16587

\subsection{7/12.2584921}

Proceedings of SPIE - The International Society for Optical Engineering

All content in PEARL is protected by copyright law. Author manuscripts are made available in accordance with publisher policies. Please cite only the published version using the details provided on the item record or document. In the absence of an open licence (e.g. Creative Commons), permissions for further reuse of content should be sought from the publisher or author. 


\section{Ikonos Satellite imagery for NDVI related assessment applied to land clearance studies}

Lavers, Chris, Mason, Travis

Chris R. Lavers, Travis Mason, "Ikonos Satellite imagery for NDVI related assessment applied to land clearance studies," Proc. SPIE 11534, Earth Resources and Environmental Remote Sensing/GIS Applications XI, 1153417 (23 September 2020); doi: 10.1117/12.2584921

SPIE. Event: SPIE Remote Sensing, 2020, Online Only 


\title{
IKONOS SATELLITE IMAGERY FOR NDVI RELATED ASSESSMENT APPLIED TO LAND CLEARANCE STUDIES
}

\author{
Chris R. Lavers*a Travis Mason* ${ }^{* b}$ \\ ${ }^{a}$ Dartmouth Centre for SeaPower and Strategy, Plymouth University at Britannia Royal Naval \\ College, College Way, Dartmouth, Devon, TQ6 0HJ; \\ ${ }^{\mathrm{b}}$ Southampton Channel Coastal Observatory, National Oceanography Centre, European Way, \\ Southampton, \\ SO14 3ZGH, UK;
}

\begin{abstract}
High-resolution satellite imagery permits verification of land clearance violations across borders due to unstable regimes or socio-economic upheaval. Without access to such areas to validate allegations remote sensing tools and techniques use are very important. Imagery-based assessment can quantify radiometrically calibrated normalised difference vegetation index (NDVI) and temporal changes evaluating displacement in the 2005 Porta Farm Zimbabwe clearances. Future nearreal time space-based monitoring would benefit human rights observers and networks.
\end{abstract}

Keywords: Space-based platforms, man-made land clearance, NDVI assessment.

\section{INTRODUCTION}

Satellite based imagery now provides an essential geographical tool to help remotely confirm allegations of human rights abuse, especially large-scale land clearing. Resource, political, or ethnic driven conflicts place human assessors in danger, notably if a party does not want operations seen, potentially by global media. As non-governmental workers are 'barred' on the pretext of safety from conflict areas, satellite imagery may be the only recourse to analyse and study these incidences.

Large-scale land clearance can be a consequence of unstable economies or regimes, increased economic globalisation or climate change. These changes may exacerbate national instabilities affecting those at the bottom of the socio-economic scale hardest [1]. Frequent conflict, economic hardship or population displacement will occur under such pressure; so documenting such cases may help provide baseline data to mitigate similar future events. In 2005 - 2006, confirmed violations occurred across Zimbabwe, clearing long established communities such as the small-scale farming and husbandry of Porta Farm. In May 2005 the government began Operation Restore Order (or Murambatsvina "Clear the dirt" in the Shona language), a series of forced evictions, demolishing homes and businesses. One report estimated the total Zimbabwe internally displaced people number in this period at 700,000 [2]. In late June 2005, the government conducted the clearance after a long legal fight [3]. In July 2005 bulldozers executed the main demolition phase with United Nations human rights monitors reporting several deaths, including children. Under international law, forced evictions or demolition of deemed illegal structures are themselves illegal actions. The United Nations Commission for Human Rights (UNCHR) states 'the practice of forced evictions constitutes a gross violation of human rights, in particular the right to adequate housing' [4]. The societal implications and a critical overview of the background planning related issues and future implications surrounding Porta Farm is discussed elsewhere [5].

*christopher.lavers@plymouth.ac.uk +044 1803 677218; fax +044 1803 6772015;

Earth Resources and Environmental Remote Sensing/GIS Applications XI,

edited by Karsten Schulz, Proc. of SPIE Vol. 11534, 1153417 • ( ) 2020

SPIE · CCC code: $0277-786 X / 20 / \$ 21 \cdot$ doi: $10.1117 / 12.2584921$

Proc. of SPIE Vol. 11534 1153417-1 
We have used recent technological developments in this area, with image processing methods, to observe several regions international human rights concerns in Sudan [6], Burma [6], and Zimbabwe [7], to quantify them, reviewing the challenges in confirming eyewitness allegations vital for effective response. We focus here on quantified land clearance impact at Porta Farm in 2005, one recorded displacement in the 2005 - 2006 clearances affecting townships across Zimbabwe. High-resolution human rights satellite monitoring was proposed in 19998 but awaited satellites like IKONOS 2 and Quickbird 2 (October 2001) with one metre or less resolution for commercial remote GIS-related surveillance applications. Satellite imagery provides key tools for detailed map making vital for distribution of key resources such as food and water, (e.g. United Nations Institute for Training and Research satellite imagery products). We focus here on quantified manmade population displacement derived image products with or without full radiometric calibration, applicable to mass burial detection [8] and other conflict driven factors [9]. Our main aim was to evaluate if IKONOS could accurately image a reported clearance, quantify it, or outline existing buildings. Substantial work on mapping destroyed building structures has been conducted by the American Association for the Advancement of Science [10], however none of their work has looked at multispectral changes due to manmade building removal with consequent land cover changes.

\section{METHODOLOGY}

Study Area The area is shown in fig. 1 indicated by reference to Harare, the capital with coordinates: nwLat-17.84, nwLong30.75, seLat-17.88, seLong30.80, taken on 25th July 2000 and 15th Sept. 2006. ArcGIS 10.2 was used with GeoTiff files to map buildings before clearance. Overlap regions were extracted in multiple bands, creating a map of removed buildings recorded by digitising polygons manually in a previous report [11] (fig. 2 and overview in insert). The settlement was $257 \mathrm{~m}$ wide, $648 \mathrm{~m}$ long, $66536 \mathrm{~m}^{2}$ area fig. 2. Buildings removed/destroyed. Fig. 2 records the colour code: red $=$ small dwellings, green $=$ large buildings: possible commercial/civic/public facilities .
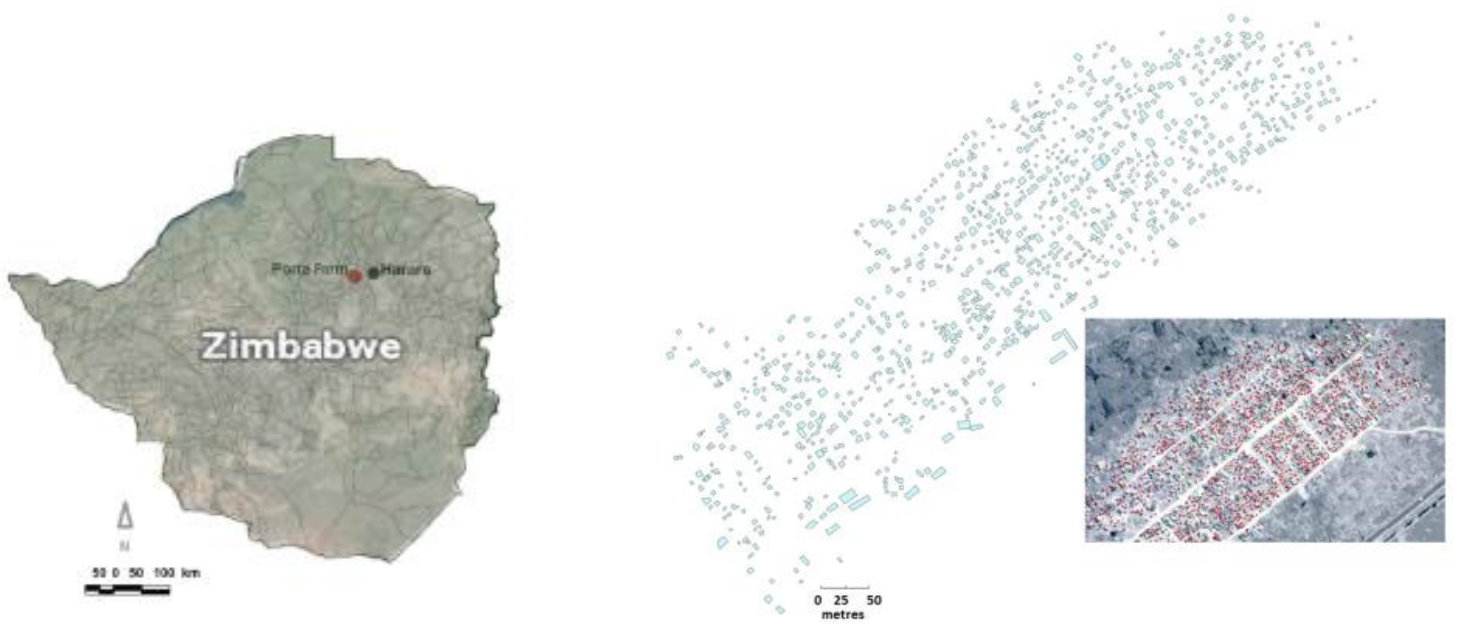

Figure 1. Porta Farm, Zimbabwe. Figure 2. Porta Farm Settlement Removed buildings plotted in ArcGIS. 
Image data processing Geometrically rectified IKONOS images were provided by the GeoEye Foundation. The methodology, fig. 3, took Digital Number (DN) sensor values, using a radiometric calibration to convert DN values to at sensor spectral radiance, and then converted spectral radiance to at sensor apparent reflectance [12].

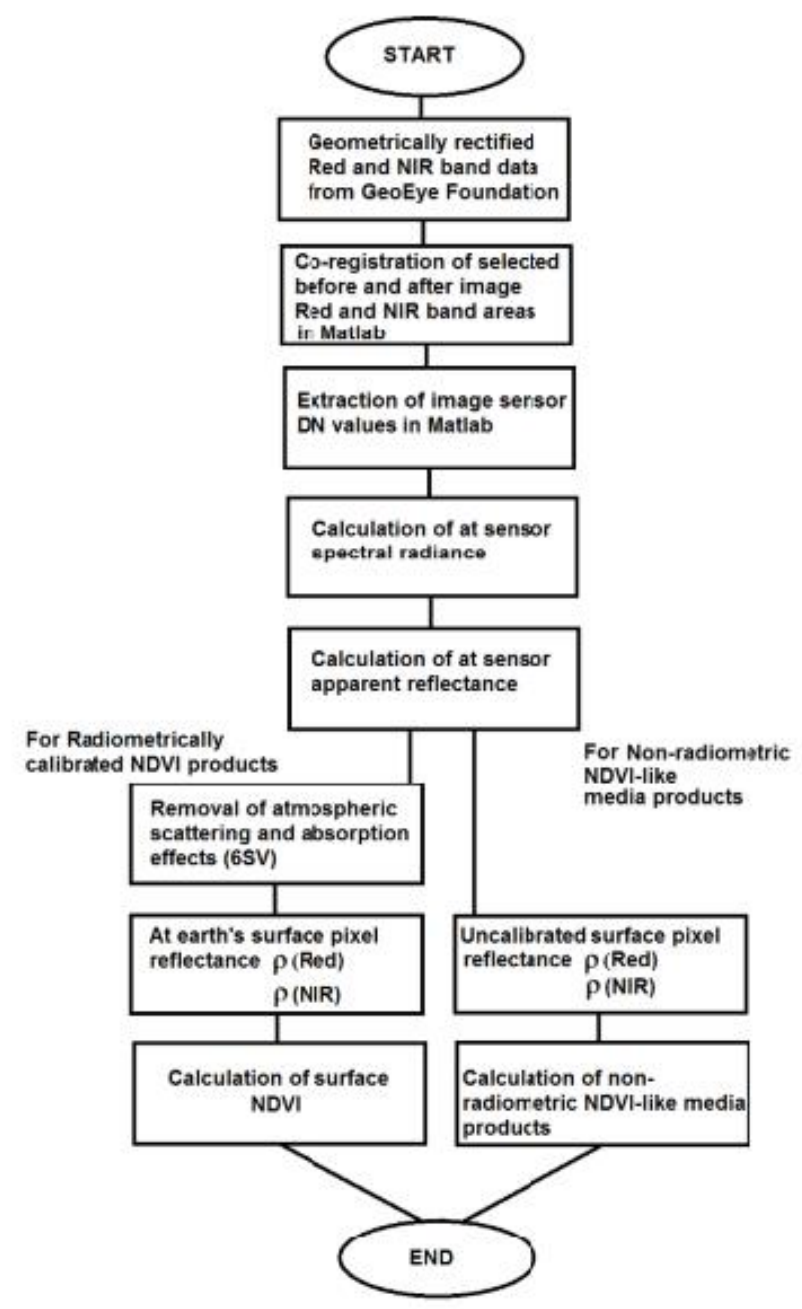

Figure 3. Methodology of NDVI Workflow Analysis.

The radiance correction [12] was followed by removal of atmospheric effects due to absorption and scattering with the Second Simulation of a Satellite Signal in the Solar Spectrum-Vector (6SV) method [13], yielding reflectance of pixels at earth surface. $6 \mathrm{~S}$ code enables accurate satellite observation simulation, accounting for elevated targets, anisotropy and gas absorption based on a method of successive orders of scatterings approximations [14]. Land use/cover change detection and analysis Landsat TM is a multispectral satellite providing visible and NIR imagery to monitor land cover and land use, or manage land change. IKONOS 2 is a multispectral satellite with $1 \mathrm{~m}$ panchromatic resolution, and four 4 metre bands (0.42 - 0.52, 0.52 - 0.60, 0.63 - 0.69 and NIR $0.76-0.90$ microns). IKONOS panchromatic and four metre band combinations provide images similar to Landsat TM products. Manual building structure identification was time 
consuming; it is efficient to identify large-scale clearance with minimal human input so a pre-detection non-radiometric Matlab process was chosen to locate large change areas for human rights or media-related analysis similar to Landsat NDVI. Humanitarian NDVI-related output doesn't require radiometric calibration based on Landsat methodology [15]. IKONOS calibrated NDVI isn't identical to Landsat, due to band differences, and with IKONOS there are less bands. Human rights observers aren't interested in radiometric products, so non-radiometric assessment is legitimate. However, as an assessment factor on displaced communities, it is useful sometimes, requiring geometric correction and coregistration, with calibration for at-aperture spectral radiance, and at surface reflectance to correctly calculate vegetation products [16]. Matlab allows wide area assessment of cover quickly, co-registering before and after imagery in single or multiple bands, ortho-rectifying pixel to pixel on scenes. Matlab elements then undergo matrix manipulation. Simple analysis uses:

\section{IKONOS}

$$
\text { NDVI }=\left(\rho_{\text {NIR }}-\rho_{\text {Red }}\right) /\left(\rho_{\text {NIR }}+\rho_{\text {Red }}\right)
$$

NDVI is usually applied to vegetative land cover, or normalised media-related temporal imagery $\mathrm{C}_{\mathrm{T}}$ :

$$
\mathrm{CT}=\left(\rho_{\text {After }}-\rho_{\text {Before }}\right) /\left(\rho_{\text {After }}+\rho_{\text {Before }}\right)
$$

where $\rho$ is the satellite camera's DN with an index between modular values 0 to 1 .

Media outlets don't usually want or require NDVI; both military and human rights surveillance operations often use single band comparison.

\section{RESULTS AND DISCUSSION}

To identify large-scale clearance with minimal human input pre-detection non-radiometric Matlab processing located large building change areas quickly, without calibration. Panchromatic data for both dates was co-registered before clearance and after for building removal identification.

\subsection{Satellite imagery of Porta Farm, before and after land clearance}

3.1.1. Main Inhabited Porta Farm Area Fig. 4a (left) the before land clearance image shows Porta Farm densely inhabited (25th July 2000) whilst fig. 4b (right), the after land clearance image, shows the same area several years later (15th September 2006) plotted using Matlab in colormap(gray).
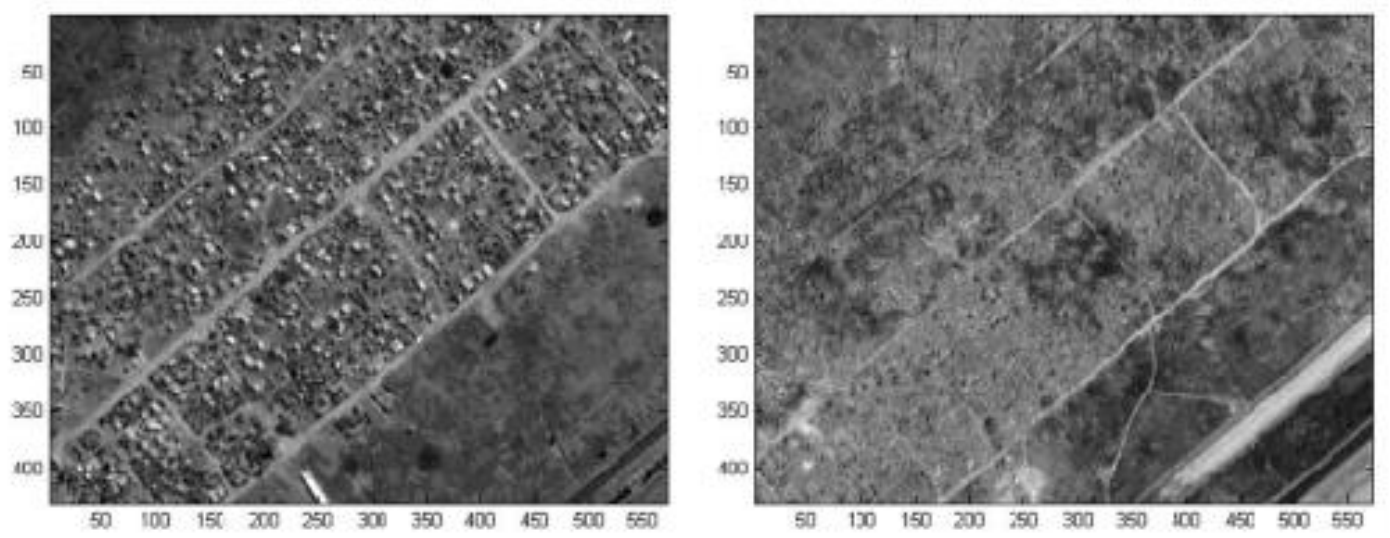

Fig.4a left (before land clearance shows Porta Farm densely inhabited 25th July 2000), fig. 4b right (after clearance 15th Sept. 2006) plotted in colormap (gray). 
Changes between the two selected regions represented by the paired images in figure 4 are dramatic: no dwellings are present in fig. $4 \mathrm{~b}$, with a few new structures added. It is unclear if these new structures are occupied, without conducting ground truthing. Initial analysis extracted GeoTiff file regions in ArcGIS 10 as discussed in the Methodology section.

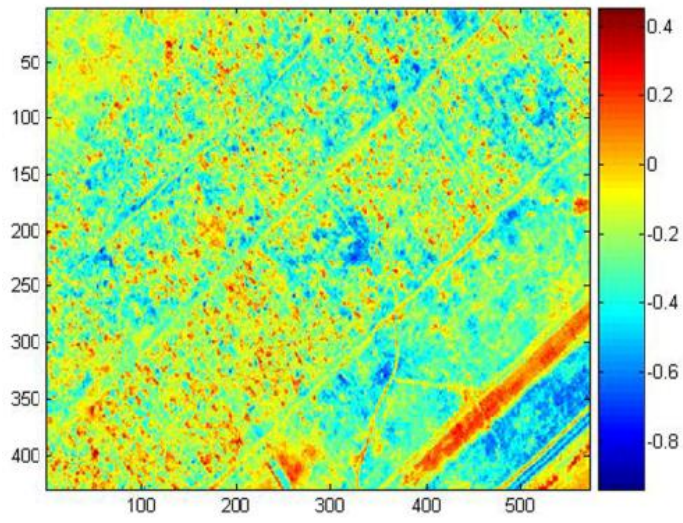

Figure 5 Temporal change index between the before and after dates of figure 4 .

Difference values fluctuate greatly, with temporal change $C_{T}$ plots fig. 5 for large area normalisation plotted in colormap (jet). Changes between images are dramatic: few dwellings are present in fig. $4 \mathrm{~b}$, with a few structures added; it is unclear if these are occupied without ground truthing. Temporal change highlights residential areas surrounded by subsistence farmland (North) of varied size and shape. Positive contrast is seen in some areas e.g. road construction (South East quadrant pixel 400 , in a generally $45^{\circ}$ South West to North East direction) with noise-like dwellings on the usual search-scale. Median-based image processing may remove point salt and pepper noise, yet preserve real artefacts with noise-like appearance.

\subsubsection{South of Porta Farm}

Radiometric NDVI was analysed before fig. 6a left, and after fig. $6 \mathrm{~b}$ middle for at aperture apparent reflectance values with IKONOS red and Near Infra Red bands, co-registered with the NDVI workflow diagram (fig. 3) and equations discussed to yield at sensor apparent reflectance changes. South of the clearance is mostly new horticulture or roads fig. 6b. Most data is in the range $0-0.5$ with areas of low NDVI. An appropriate radiometric calibration (6SV) method (fig. 3) corrected at-aperture spectral radiance to provide normalised NDVI for pixels at earth's surface for our IKONOS 2 multispectral data (fig. $6 \mathrm{c}$ right). Normalisation changes contrast magnitude but still retains features observed previously (see figures 6a and $6 \mathrm{~b}$ respectively for comparison). Corrected at earth NDV shows linear features in change in fig. $6 \mathrm{c}$. Fig.6 images are radiometrically calibrated at surface NDVI image, plotted in colormap (jet).
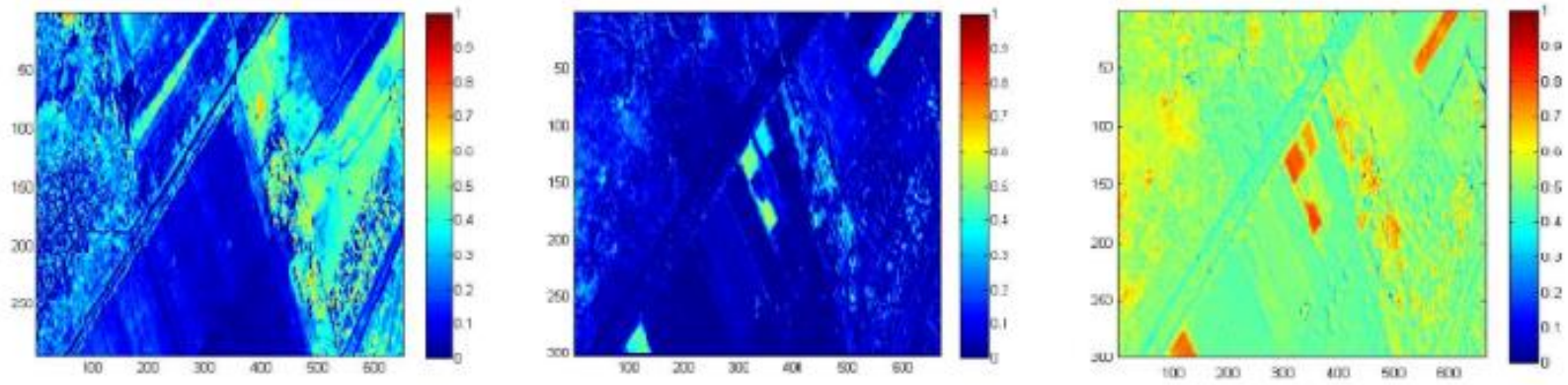

Fig 6a before clearance (left), $6 \mathrm{~b}$ after clearance (middle), fig. 6c at earth radiometrically calibrated NDVI, right. 


\subsubsection{Lake Chivero}

The third region of the Porta Farm study considered the NDVI changes in the vicinity of the littoral shore of Lake Chivero, visible to the South East of the land clearance (which was located delineated near the newly farmed fields outlined top left in the image). Imagery on the two previous set dates in both visible (red) and the Near Infra Red (NIR) were compared in an identical way to the two previous sections, and in so doing similar image data products were produced that again show the NDVI across the selected regions. The edge of the lake is highlighted in the colormap palette as shown in fig. 7. for the Post clearance NDVI plotted in colormap (jet).

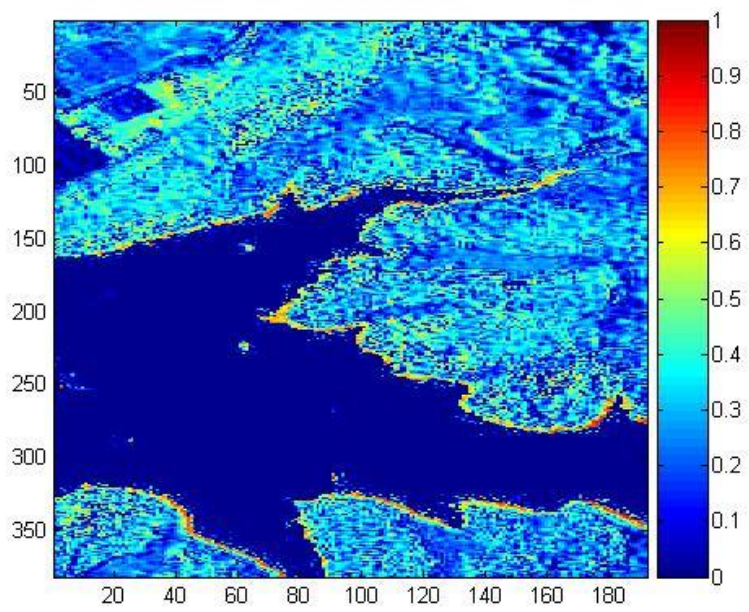

Figure 7. Post clearance NDVI plotted in colormap (jet).

This work considers space-based monitoring for human rights observation and is not concerned specifically with calibration. Correct reflectance is vital to compare data accurately with predicted reflectance as a function of incident angle derived from a wavelength dependent optical permittivity scattering matrix formalism [17]. Another Zimbabwe land study identified roads beside minefields, lost minefield perimeter vegetation, or mixed agricultural area regeneration from remotely sensed data [18]. In another agricultural study, sudden reflectance change was associated with crops and re-vegetation associated with abandoned agricultural land on imagery separated by a minimum of 3 years [19-20], a requirement met over our data period. Witmer also examined Bosnia Herzegovinan conflict Landsat imagery, developing vegetation detection algorithms [9].

\section{SUMMARY}

Comparison of before and after IKONOS satellite imagery can provide evidence to corroborate altered land use: building removal, addition, and agricultural changes. Initial manual assessment was used to map Porta Farm but was time consuming.

Matlab software enabled large area initial assessment with suitable algorithms to provide rapid change assessment, with false colour contrast delineating man-made boundaries, e.g. fields, from natural ones, such as lake edges. Suitable Matlab spectral and temporal comparisons can provide radiometrically calibrated and non-radiometrically calibrated NDVIproducts to quantify and visualise for media-related products a wide range of human rights-related issues. The use of automation and a range of digital filters in conjunction with space-based wide scale monitoring will be of future benefit to remotely located international human rights observers to provide perishable information in a short time scale.

The postscript of what happens to those who are displaced in such land clearances, now some fifteen years on, is sadly not a happy one. For those that left Porta Farm, ironically an established settlement which had developed over fifteen years from previous displaced settlements, generated unsurprisingly the establishment of further settlements, such as the Hopley Farm Settlement near Harare, Zimbabwe. As another author has put it "The persistence of urban challenges in 
emerging communities makes it difficult to attain inclusive, resilient, sustainable, and safe communities" [21]. This chronic ongoing situation has a detrimental impact on the socioeconomic, political, and environmental situation of both settlement residents, set at odds with those in Harare and elsewhere; conflicts arise between those that haves and more strictly those that have not yet had what they have taken away. Communities are not only vulnerable to disease outbreaks such as endemic cholera, typhoid, malaria, but other transmissible diseases such as the current novel coronavirus outbreak, or potentially much more dangerous viruses, such as Ebola, if such a pandemic were to arise. Besides this any local impacts of natural disasters and climate change, such as flooding or drought will impact local harvests, exacerbating the difficulties already underlying such poor communities. Fifteen years later, at the same point that Porta Farm was cleared, the current Hopley settlement is still developing, but can be characterised by a general lack of basic service provision, displacement of households, evictions, and intimidation. How residents can attempt to build lasting communities, relationships, and overall generational improvements in living standards, or wealth generation, with multidecadal long term threats of forced dispersion and displacement whilst trying to go about their daily lives is bleak and unclear, without strong protection in law.

\section{ACKNOWLEDGEMENTS}

Dr Lavers thanks the DigitalGlobe Foundation [22] (at the time of the award this was the GeoEye Foundation) for IKONOS 2 imagery provided from the GeoEye Foundation imagery archive for this work. The authors also thank Mrs Suzanne Trimel (formerly Amnesty USA) for access to additional Porta Farm based imagery.

\section{REFERENCES}

[1] Mabey, N., "Delivering Climate Security International Security Responses to a Climate Changed World", Whitehall Paper 69, RUSI, (2008).

[2] Zimbabwe shattered lives- the case of Porta Farm, Amnesty International and Zimbabwe Lawyers for Human Rights, Summary: 31/03/2006 AI Index: AFR 46/004/2006, (2006).

[3] ICESCR (International Covenant on Economic, Social \& Cultural Rights), Article 11(1), 1976 <http://www.ohchr.org/EN/ProfessionalInterest/Pages/CESCR.aspx< (last accessed 21st March 2017.)

[4] UNCHR, UN Commission on Human Rights Resolution 1993/77 para 1. (1993)

[5] Fegue, C., 'Informal settlements' planning theories and policy-making in Sub-Saharan Africa- from 'site' to 'people': a critical evaluation of operations 'Murambatsvina' and 'Garikai' in Zimbabwe”, International Journal of Sustainable Development and Planning, Vol. 2, No. 4 (2007) 445-460 (2007).

[6] Lavers, C., Bishop, C., Hawkins, O., Grealey, E., Baroness Cox, C., Thomas, D., and Trimel, S., “Application of satellite imagery to monitoring human rights abuse of vulnerable communities, with minimal risk to relief staff'. Sensors and their Applications XV Journal of Physics: Conference Series 178012039 (Bristol IOP Publishing) (2009).

[7] Lavers, C.R., and Mason, T.R. High-resolution IKONOS satellite imagery for normalized difference vegetative index-related assessment applied to land clearance studies Journal of Applied Remote Sensing 11(3), (2017).

[8] Norton, E., Ford, A., and Cheetham, P., "The Prospection of Mass Graves: A Multi-Platform Approach". Proceedings of the Remote Sensing and Photogrammetry Society Annual Conference, (2013).

[9] Witmer, D.W., and O' Loughlin, J., "Satellite data methods and application in the evaluation of war outcomes: Abandoned agricultural land in Bosnia-Herzegovina after the 1992-1995 conflict", Annals of the Association of American Geographers, Vol. 99, No.5, 1033-1044, (2009).

[10] American Association for the Advancement of Science <https://www.aaas.org/program/geospatialtechnologies-project> (last accessed 21st March 2017).

[11]Lavers, C., "Zimbabwe- a satellite imaging analysis of the forced demolition of Porta Farm", GeoEye Foundation report, (2011).

[12] Podger, N.E., Colwell, W.B., and Taylor, M.H., "GeoEye-1 Radiance at Aperture and Planetary Reflectance", $11 / 03 / 2011$

$<$ https://apollomapping.com/wpcontent/user_uploads/2011/09/GeoEye1_Radiance_at_Aperture.pdf > (last accessed 23rd September 2020.) 
[13] 6SV routine (<http://6s.ltdri.org/>), last accessed 23rd September 2020.

[14] Kotchenova, S.Y., Vermote, E.F., Matarrese R., and Klemm, Jr., FJ. ,"Validation of a vector version of the 6S radiative transfer code for atmospheric correction of satellite data. Part I: Path radiance", Applied Optics, Vol. 45, No. 26, (2006).

[15]Landsat calibration <http://landsat.usgs.gov/science_calibration.php> (last accessed 21st March 2017.)

[16] Myneni, R.B., Hall, F.G., Sellers, P.J., and Marshak, A.L., "The interpretation of spectral vegetation indices". IEEE Transactions on Geoscience and Remote Sensing, 33, No.2, 481-486, (1995).

[17] Ko, D., and Sambles, J.R., "Scattering method for propagation of radiation in stratified media: attenuated total reflection studies of liquid crystals", Journal of the Optical Society of America, A5, 1863, (1988).

[18] Maathuis, B.H.P., "Remote sensing based detection of minefields", Geocarto International, 18 (1): $51-60$. DOI: 10.1080/10106040308542263 (2003).

[19] Bauer, M.E., "Spectral inputs to crop identification and condition assessment", Proceedings of IEEE, 73 (6): 1071-85, (1985).

[20] Coppin, P., Jonckheere, I., Nackaerts, K., Muys, B., and Lambin, E. "Digital change detection methods in ecosystem monitoring: A review", International Journal of Remote Sensing, 25 (9): 1565- 96. DOI: 10.1080/0143116031000101675 (2004).

[21] Matamanda, A.R., "Living in an Emerging Settlement: the Story of Hopley Farm Settlement, Harare Zimbabwe" ORCID: orcid.org/0000-0001-5260-55601 Published: 20 June 2020, Urban Forum (2020).

[22] Digital Globe Foundation, <www.digitalglobefoundation.org/> (last accessed 21st March 2017). 